\title{
JNPH
}

Volume 5 No. 1 (Juli 2017)

(C) The Author(s) 2017

\section{EFEKTIVITAS PENERAPAN TERAPI MUSIK KERONCONG TERHADAP PENURUNAN TINGKAT DEPRESI PADA LANJUT USIA (LANSIA) DI BPPLU PROVINSI BENGKULU}

\section{EFFECTIVENESS OF IMPLEMENTATION OF KERONCONG MUSIC THERAPY TO DECREASE OF DEPRESSION ON ELDERLY (LANSIA) IN BPPLU BENGKULU PROVINCE}

\author{
PIPIT PITASARI, DKK \\ SEKOLAH TINGGI ILMU KESEHATAN DEHASEN BENGKULU \\ Email : pipit_pipitpitasari07@gmail.com (No Hp : 082281672862)
}

\begin{abstract}
ABSTRAK
Menurut organisasi kesehatan dunia, WHO seseorang disebut lanjut usia (elderly) jika berumur 60-74 tahun. Depresi adalah suatu perasaan sedih dan pesimis yang ditandai yang berhubungan dengan suatu penderitaan dapat berupa serangan yang ditunjukan pada diri sendiri atau perasaan marah yang dalam (Nugroho, 2000) dalam (Aspiani, 2014). Menurut Wigram (dalam Djohan, 2006) terapi musik adalah penggunaan musik dalam lingkup klinis, pendidikan, dan sosial bagi klien atau pasien yang membutuhkan pengobatan, pendidikan atau intervensi pada aspek sosial dan psikologis. Tujuan penelitian ini adalah untuk mengetahui tingkat depresi lansia sebelum dan sesudah dilakukan terapi musik keroncong serta untuk mengetahui efektifitas pemberian terapi musik keroncong terhadap penurunan tingkat depresi pada lansia. Metode yang digunakan adalah Metode jenis metode uji statistik menggunakan uji $t$ (pired samples statiks), data yang dikumpulkan dengan menyebarkan kuisioner pada 25 orang reponden di BPPLU Provinsi Bengkulu pada bulan Maret s/d Juli 2017 dengan teknik random (pilihan). Hasil analisis uji $t$ (pirde samples statiks) bahwa lebih dari bahwa rata-rata nilai tingkat depresi pada lansia sebelum dilakukan terapi musik adalah, 12,5 nilai yang paling rendah berjumlah 5 dan nilai tertinggi berjumlah 26. Hasil penelitian menunjukkan bahwa sebelum dilakukan terapi musik lansia mengalami depersi ringan 3 orang, depresi sedang 18 orang, dan depresi berat 4 orang. bahwa rata-rata nilai tingkat depresi pada lansia sebelum dilakukan terapi musik adalah, 8,4 , nilai yang paling rendah berjumlah 5 dan nilai tertinggi berjumlah 17. Hasil penelitian menunjukkan bahwa sesudah dilakukan terapi musik lansia mengalami depersi ringan 15 orang, depresi sedang 9 orang, dan depresi berat 1 orang. Terapi musik kerocong mempunyai dampak yang signifikan terhadap penurunan tingkat depresi.
\end{abstract}

Kata Kunci: lansia, depresi, terapi musik

\begin{abstract}
According to the World Health Organization WHO, one is called elderly if aged 60-74 years. Depression is a feeling of sadness and pessimism that is characterized in relation to an affliction can be a self-induced attack or a deep feeling of anger (Nugroho, 2000) in (Aspiani, 2014). According to Wigram (in Djohan, 2006) music therapy is the use of music in the clinical, educational, and social sciences for clients or patients who need treatment, education or
\end{abstract}


intervention on social and psychological aspects. The purpose of this study was to determine the level of depression of elderly before and after keroncong music therapy and to determine the effectiveness of keroncong music therapy to decrease the level of depression in the elderly. The method used is the method of statistical test method using t-test (pired samples statiks), data collected by distributing questionnaires to 25 respondents in BPPLU Bengkulu Province in March to July 2017 with random technique (option). The results of $t$ test analysis (pirde samples statiks) that more than that the average value of the depression rate in the elderly before the music therapy is, 12.5 the lowest value amounted to 5 and the highest value amounted to 26. Results showed that before the music therapy the elderly experienced mild depression 3 people, moderate depression 18 people, and severe depression 4 people. That the average value of depression level in the elderly before the music therapy is, 8.4, the lowest value amounted to 5 and the highest score amounted to 17 . The results showed that after the music therapy elderly mild depression 15 people, depression was 9 people, and major depression 1 person. Keroncong Music therapy have a significant impact on the decrease of depression level.

Keywords: elderly, depression, music therapy

\section{PENDAHULUAN}

Di Indonesia lanjut usia (Lansia) yang terus meningkat dapat menjadi aset bangsa bila sehat dan produktif. Namun Lansia yang tidak sehat dan tidak mandiri akan berdampak besar terhadap kondisi sosial dan ekonomi bangsa. Secara global populasi lansia diprediksi terus mengalami peningkatan. Populasi lansia di Indonesia diprediksi meningkat lebih tinggi dari pada populasi lansia di dunia setelah tahun 2010. Sebagian besar usia lanjut dapat mempertahankan kegiatan mental baik secara intelektual maupun emosiaonal sepanjang hidup mereka. Sebagian lagi, ketika memasuki tahap usia lanjut menujukkan perubahan-perubahan sifat seperti kehilangan minat terhadap semua kegemaran semasa mudahnya, sikap menjadi kaku atau tidak mempunyai keinginan terhadap hal-hal yang baru. Mempersiapkan kondisi mental yang sehat dan aktif pada msa tua, membutuhkan pemeliharaan secara terus menerus baik intelektual maupun emosional, yang tidak saja mempertahankan daya pikirnya, akan tetapi juga dapat mencegah perasaan cemas dan depresi. Salah satu solusi penurunan tingkat depresi pada lansia yaitu pemberian terapi musik keroncong untuk membantu mengekspresikan perasaan, membantu rehabilitasi atas fisik, memberi pengaruh positif terhadap kondisi suasana hati dan emosi meningkatkan memori, serta menyediakan kesempatan yang unik untuk berinteraksi dan membangun kedekatan emosional. Sehingga diharapkan dapat membantu mengatasi depresi (Djohan, 2006). Campbell (2005) menyatakan bahwa musik yang didengar seseorang akan disalurkan oleh syaraf auditory kemudian aktivitas suara yang ditimbulkannya direkam pada EEG (Electric Ensepealo Gram) terutama pada lapisan korteks serebri yang superficial, yang kemudian mengalir antara fluktuatuing sipoles yang terbentuk dari dendrti-dendrit sel kortikal dan badan sel. Dendrti-dendrit tersebut berorienstasi serupa dan merupakan unit-unit yang bersatu dengan kompleks pada korteks serebri. Aktivitas banyak unit dendrit tersebur berjalan sinkron untuk membentuk corak gelombang alfa yang menandakan kondisi heightened awareness dan tenang.

Pemberian musik keroncong dapat mempengaruhi gelombang otak menuju gelombang otak yang diinginkan. Prinsip pemberian terapi musik keroncong adalah dengan memberikan suara yang berbeda tempo irama lagu, dan dapat mempengaruhi telinga dan otak kemudian akan menangkap selisih dari perbedaan frekuensi tersebut kemudian mengikutinya sebagai gelombang otak.

\section{METODE PENELITIAN}

Metode yang digunakan dalam penelitian 
ini adalah jenis metode uji statistik menggunakan uji $t$ (pired samples statiks). Waktu penelitian selama 5 bulan dari bulan Maret s/d Juli 2017 dan tempat penelitian adalah di Balai Pelayanan dan Penyantunan Lanjut Usia di Provinsi Bengkulu. Pengumpulan data populasi dalam penelitian ini seluruh lansia di Balai Pelayanan dan Penyantunan Lanjut Usia di Provinsi Bengkulu dengan jumlah pasien yang mengalami depresi berjumlah 35 orang dari jumlah seluruh Lansia 60 orang akan tetapi yang masuk dalam kriteria 25 orang dengan tehnik pengambilan sampel rendem (pilihan).

\section{HASIL PENELITIAN}

Hasil penelitian awal pada PKM ini telah dilakukan pengidentifikasian masalah dan pengukuran tingkat depresi tahap pertama, dengan menggunakan kuesioner Beck Depression Inventory (BDI). Adapun hasil yang telah dicapai pada penelitian ini adalah sebagai berikut :

\section{Tabel 1 Distribusi frekuensi nilai responden sebelum melakukan terapi musik keroncong di BPLU Provinsi Bengkulu}

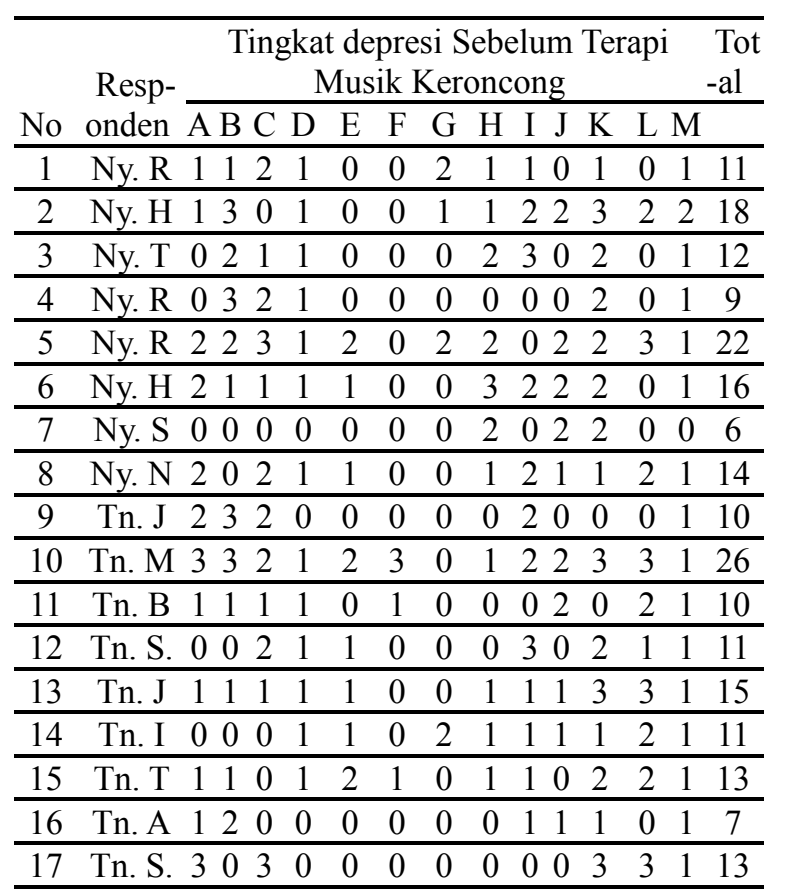

\begin{tabular}{cccccccccccccccc}
\hline 18 & Tn. M & 0 & 0 & 0 & 0 & 1 & 0 & 0 & 2 & 2 & 0 & 2 & 1 & 1 & 9 \\
\hline 19 & Tn. S. & 1 & 1 & 1 & 0 & 0 & 0 & 0 & 1 & 1 & 1 & 2 & 2 & 1 & 11 \\
\hline 20 & Tn. Y & 3 & 0 & 2 & 0 & 0 & 0 & 0 & 2 & 2 & 1 & 2 & 2 & 2 & 16 \\
\hline 21 & Tn. B & 1 & 0 & 0 & 0 & 2 & 0 & 2 & 1 & 1 & 2 & 1 & 2 & 1 & 13 \\
\hline 22 & Tn. I & 1 & 1 & 1 & 3 & 0 & 2 & 0 & 0 & 1 & 1 & 1 & 1 & 0 & 12 \\
\hline 23 & Tn. A & 0 & 0 & 2 & 0 & 0 & 0 & 0 & 3 & 1 & 2 & 1 & 0 & 1 & 10 \\
\hline 24 & Ny. I & 0 & 1 & 1 & 1 & 1 & 1 & 0 & 0 & 1 & 0 & 3 & 3 & 1 & 13 \\
\hline 25 & Tn. M & 0 & 0 & 2 & 1 & 0 & 0 & 0 & 0 & 1 & 0 & 0 & 0 & 1 & 5 \\
\hline Jumlah & 2 & 3 & & & & & & 3 & 2 & & & 2 & \\
Nilai & 6 & 26 & 1 & 18 & 15 & 8 & 9 & 25 & 1 & 3 & 42 & 34 & 5 & 313 \\
\hline
\end{tabular}

Tabel diatas menunjukkan bahwa ratarata nilai tingkat depresi pada lansia sebelum dilakukan terapi musik adalah, 12,5 nilai yang paling rendah berjumlah 5 dan nilai tertinggi berjumlah 26 .

Tabel 2 Distribusi frekuensi nilai responden sesudah melakukan Terapi Musik Keroncong di BPPLU Provinsi Bengkulu

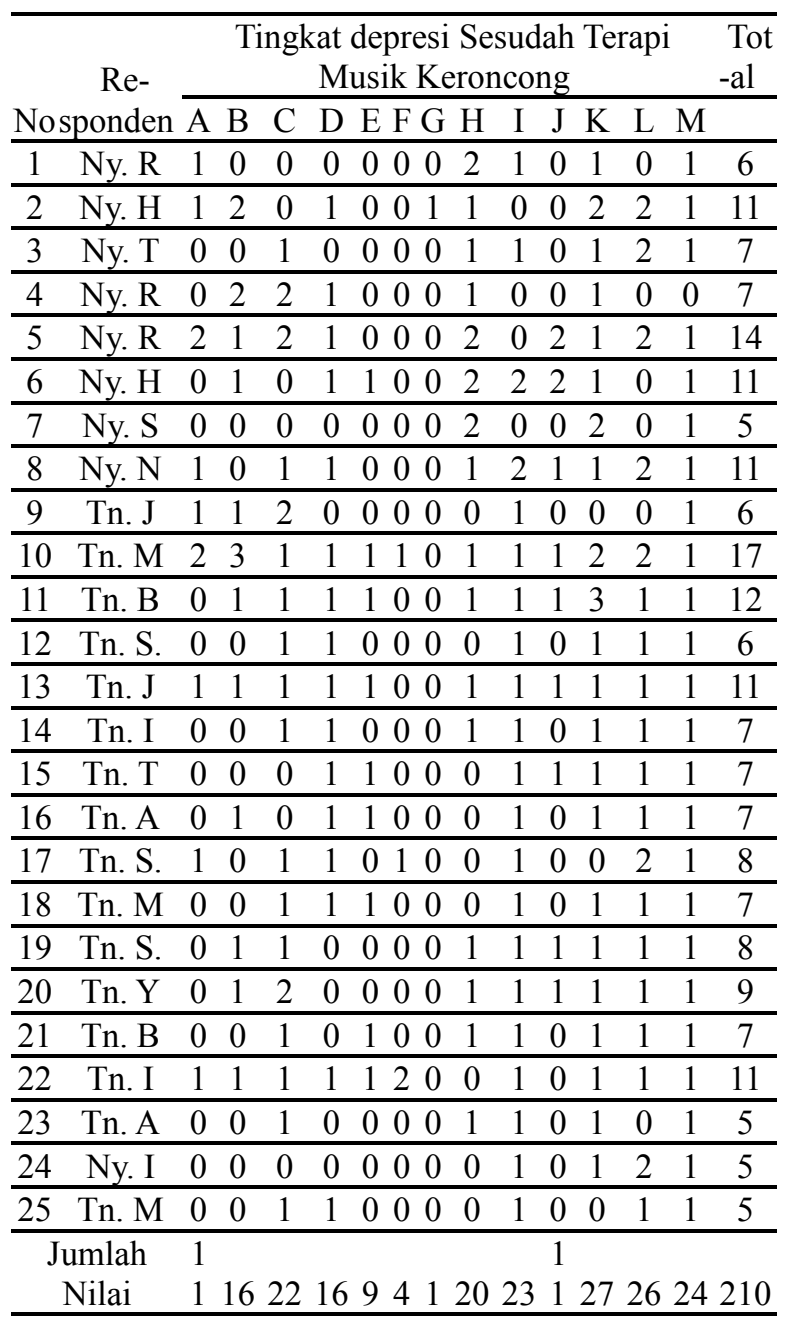


Tabel diatas menunjukkan bahwa ratarata nilai tingkat depresi pada lansia sebelum dilakukan terapi musik adalah 8,4 , nilai yang paling rendah berjumlah 5 dan nilai tertinggi berjumlah 17.

Tabel 3 Distribusi Frekuensi Nilai Persentase Perindividu Selisih Sebelum dan Sesudah Melakukan Terapi Musik Keroncong di BPPLU Provinsi Bengkulu

\begin{tabular}{cccccc}
\hline & $\begin{array}{c}\text { Respon- } \\
\text { No }\end{array}$ & den & Sebelum & Sesudah & Selisih Persentase \\
\hline 1 & Ny. R & 11 & 6 & 5 & $45 \%$ \\
\hline 2 & Ny. H & 18 & 11 & 7 & $38,9 \%$ \\
\hline 3 & Ny. T & 12 & 7 & 5 & $41,7 \%$ \\
\hline 4 & Ny. R & 9 & 7 & 2 & $22 \%$ \\
\hline 5 & Ny. R & 22 & 14 & 8 & $36 \%$ \\
\hline 6 & Ny. H & 16 & 11 & 5 & $31 \%$ \\
\hline 7 & Ny. S & 6 & 5 & 1 & $16,7 \%$ \\
\hline 8 & Ny. N & 14 & 11 & 3 & $21 \%$ \\
\hline 9 & Tn. J & 10 & 6 & 4 & $40 \%$ \\
\hline 10 & Tn. M & 26 & 17 & 9 & $34,6 \%$ \\
\hline 11 & Tn. B & 10 & 12 & 2 & $-20 \%$ \\
\hline 12 & Tn. S. & 11 & 6 & 5 & $45 \%$ \\
\hline 13 & Tn. J & 15 & 11 & 4 & $26,7 \%$ \\
\hline 14 & Tn. I & 11 & 7 & 4 & $36 \%$ \\
\hline 15 & Tn. T & 13 & 7 & 6 & $46 \%$ \\
\hline 16 & Tn. A & 7 & 7 & 0 & $0 \%$ \\
\hline 17 & Tn. S. & 13 & 8 & 5 & $38 \%$ \\
\hline 18 & Tn. M & 9 & 7 & 2 & $22 \%$ \\
\hline 19 & Tn. S. & 11 & 8 & 3 & $27 \%$ \\
\hline 20 & Tn. Y & 16 & 9 & 7 & $43,8 \%$ \\
\hline 21 & Tn. B & 13 & 7 & 6 & $46 \%$ \\
\hline 22 & Tn. I & 12 & 11 & 1 & $41,7 \%$ \\
\hline 23 & Tn. A & 10 & 5 & 5 & $50 \%$ \\
\hline 24 & Ny. I & 13 & 5 & 8 & $61,5 \%$ \\
\hline 25 & Tn. M & 5 & 5 & 0 & $0 \%$ \\
\hline & & & & & \\
\hline
\end{tabular}

\section{PEMBAHASAN}

Berdasarkan hasil penelitian ini menunjukkan bahwa adanya penurunan tingkat depresi pada lansia setelah mendapatkan terapi musik keroncong. Hasil penelitian menunjukkan bahwa sebelum dilakukan terapi musik lansia mengalami depresi ringan 3 orang, depresi sedang 18 orang, dan depresi berat 4 orang sedangkan setelah dilakukan terapi musik lansia mengalami depersi ringan 15 orang, depresi sedang 9 orang, dan depresi berat 1 orang.
Seperti responden Ny.R sebelum dilakukan terapi nilai kuisioner BDI mencapai 11 dan setelah dilakukan terapi musik keroncong selama \pm 2 bulan 16 kali pertemuan, dalam 1 hari responden mendapatkan terapi musik keroncong 5 menit dengan nilai kuisioner BDI turun menjadi 6 (45\%). Rata-rata responden yang mengikuti terapi musik mengalami penurunan tingkat depresi setelah mengikuti terapi musik.

\section{KESIMPULAN}

Berdasarkan hasil penelitian tentang Efektivitas penerapan terapi musik keroncong terhadap penurunan tingkat depresi pada lanjut usia (lansia) di BPPLU Provinsi Bengkulu Tahun 2017 dapat diperoleh nilai rata-rata tingkat depresi pada lansia sebelum dilakukan terapi musik keroncong berjumlah 12,5 dan lansia mengalami depresi ringan 3 orang, depresi sedang 18 orang, dan depresi berat 4 orang. Sedangkan nilai rata-rata tingkat depresi pada lansia sesudah dilakukan terapi musik keroncong berjumlah 8,4 dan lansia yang mengalami depresi sesudah dilakukan terapi musik lansia mengalami depersi ringan 15 orang, depresi sedang 9 orang, dan depresi berat 1 orang. Ada efektivitas penerapan terapi musik keroncong terhadap penurunan tingkat depresi pada lanjut usia. Dari hasil penelitian ini adalah memberikan informasi kepada petugas Badan Pelayanan dan Penyantunan Lanjut usia dalam penanganan lansia yang menderita depresi, sehingga lansia dapat meningkatkan harapan hidup.

\section{SARAN}

Agar dapat meningkatkan sosialisasi kepada pihak Balai Pelayanan dan Penyantunan Lanjut Usia untuk memberikan terapi musik kepada lansia yang mengalami depresi. Agar dapat meningkatkan harapan hidup pada lansia. 


\section{DAFTAR PUSTAKA}

Azwar Azrul,2000. Pedoman pembinaan kesehatan usia lanjut bagi petugas kesehatan, cetakan II. Jakarta : Departemen Kesehatan RI

Broker, dkk. 2001. Terapi Musik Klasik Yang Menyejukan Hati. Tathaimutzz. Edisi 2012

Depkes, 2016. Situasi Lansia Sehat, Lansia Aktif dan Produktif. Edisi 2016

Effendi dan Mukhfudli, 2009. Jurnal hasil Riset. Edisi 2013

Syifa, 2004. Jurnal Keperawatan Indonesia, Volume 12, No.2 juli 2008 : Hal 115-120

Victor Ganap, "Musik Keroncong Hanya Ada di Indonesia", Gong, Edisi 105/IX/2008 